\title{
Frequency Control of Induction Generator in Stand- alone Operation Using Bynary Logic
}

\author{
Getúlio Ribeiro Marques*, Lucas Henrique Simões*, José Manuel Esteves Vicente*, José Carlos Grilo \\ Rodrigues*, Délvio Franco Bernardes*, Angelo José Junqueira Rezek*, \\ Alexandre Viana Braga*, Valberto Ferreira da Silva*
}

\begin{abstract}
This paper presents a study for the solution to the problem of stability of the steady state frequency of a generator connected to a load, by using a binary logic control. The active power flowing in the load, influences the machine generated voltage frequency. In the present study, an induction motor has been used as generator machine. To ensure that this frequency remains constant against variation of loads, a ballast load will be used, the power of which is controlled by using a binary logic.
\end{abstract}

Keywords-Induction generator, frequency control, binary logic, ballast load.

\section{Introduction}

An electric power system must ensure the power supply to the loads in a reliable and uninterrupted manner. In addition to ensuring the continuity of energy supply, the electrical system must meet the minimum conditions for proper operation, such as the levels of amplitude and frequency of voltage. With the rapid technological advancement and resulting sophistication of electronic equipment, the range of tolerance to variation of voltage and frequency has increasingly diminished.

It is known from studies on the stability angle of rotors, of which the impacts relating to changes in active power in the loads, results in variation of the angular speed of the rotor of the generator machine and hence in the frequency range, as shown in (1), to a synchronous machine.

$$
\frac{\mathrm{d} \omega}{\mathrm{dt}}=\frac{\omega \mathrm{s}}{2 \mathrm{H}}(\mathrm{Pm}-\mathrm{Pe})
$$

Where $\omega$ is the angular velocity, $\omega$ s is the synchronous speed, $\mathrm{H}$ is the machine inertia time constant, $\mathrm{Pm}$ is the mechanical power and $\mathrm{Pe}$ is the electric power.

This paper proposes a frequency control system applicable to a generation system, in order to improve the quality of the generated energy. This system operates by placing or removing an auxiliary load, called ballast load, so as to maintain constant the electric power seen by the generator. This control will act by way of a binary logic.

\footnotetext{
*Federal University of Itajubá - UNIFEI

Brazil

Corresponding author:
}

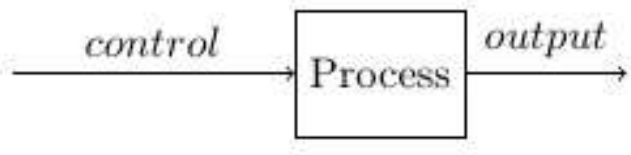

Figure 1. Control system in open loop

\section{A. Generation System}

Systems that are commonly used are comprised of an electric generator coupled to a drive shaft, which provides the mechanical energy needed for the conversion into electrical energy by the generator. Three types of electric machines can operate as traditional generators: asynchronous induction machines, synchronous machines and a DC machines. As a generator, the synchronous machine is the most used, with higher power control facility generated voltage and frequency.

Direct current motors were, for a long time, widely used as generators, however, due to their relatively high cost, and with the advent of static solid state rectifiers, this motor is increasingly obsolete as a generator. Already, the asynchronous induction motor is widely used due to its simplicity, robustness and relatively low cost [1]. This motor can also operate as a generator [2] under certain conditions. An asynchronous motor acting as a generator does not generate reactive power, on the contrary, it consumes reactive power, for this reason the use of a capacitor bank in an isolated system is required.

An interesting application of this work can be oriented to use in micro-hydro power plant (renewable energy) [3]. The idea is the implementation in a project of $30[\mathrm{~kW}]$ using induction generator, as the improvement of the actual existing project, that uses a controlled ballast load applying per phase anti-parallel thyristors. In this case there is a disadvantage of harmonic generation. The idea is then in a near future, substitute the controlled method by this one presented in this paper, in which the ballast load will be not controlled, but switched, and so there will be no harmonic generation.

\section{B. Control System}

A control system consists of a device or set of devices that govern the behavior of any system. Two types of control can be set: control in open loop and closed loop control. In open loop control, the input signal is pre-set or pre-programmed and system responses do not influence the behavior of control. Figure 1 represents the basic diagram of a control system in 


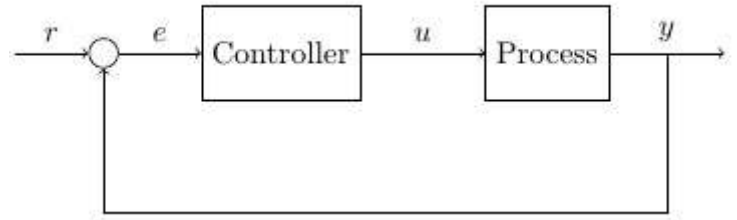

Figure 2. Closed loop control system.

open loop. In the control of the closed loop system, the control action is dependent on the output. Thus, the output is constantly monitored and its value is compared with the input signal or reference, generating an error or deviation. This process is done through an output feedback loop for comparing with the reference. The device that uses the error signal to determine or calculate the control signal to be applied to the process is called controller or compensator. Figure 2 represents the basic diagram of a control system in closed loop.

\section{Main load and ballast load}

The main load is an element that is intended to absorb the energy generated by exercising the function for which it was designed, generating work in many different ways, heat, motion, lighting, etc. The ballast load is designed to absorb exciding energy generated, and so, the active power provided by the generator remains always constant.

\section{Methodology}

For a generation system, we used an asynchronous induction generator driven by a DC motor, the speed of which is controlled by thyristors. Figure 3 shows the equipment used for the generation system and Table I shows the nameplate data of the induction motor used as generator. The reactive power is supplied by a capacitor bank, connected in delta, 30 $[\mu \mathrm{F}]$ (see figure 6 ). The frequency was controlled by a closed loop system, as shown in Figure 2. The system collects the frequency information generated by the machine and compares it with a reference value. According to the offset, the controller operates in order to fix it by sending binary logic signals for static thyristor switches, increasing or decreasing the active power absorbed by the ballast load, as needed. The number of load arrangements defines the number of possible combinations for the power absorbed by the ballast load, according to (2), where $\mathrm{n}$ is the number of available load arrangements.

$$
\text { combinations number }=2^{n}
$$

In this project, four three-phase lamp arrangements for ballast load, with their powers distributed according to (3), were used.

$$
P a=\frac{P t-\sum_{i=a+1}^{n} P i}{2^{a}-1}
$$

Where $\mathrm{Pa}$ is the arrangement of the power and $\mathrm{Pt}$ is the total power of ballast load.

Starting with a full three-phase power of 600[W], the power was found for each arrangement of ballast load, the results were:P1=320[W]; $\mathrm{P} 2=160[\mathrm{~W}] ; \mathrm{P} 3=80[\mathrm{~W}] ; \mathrm{P} 4=40[\mathrm{~W}]$.

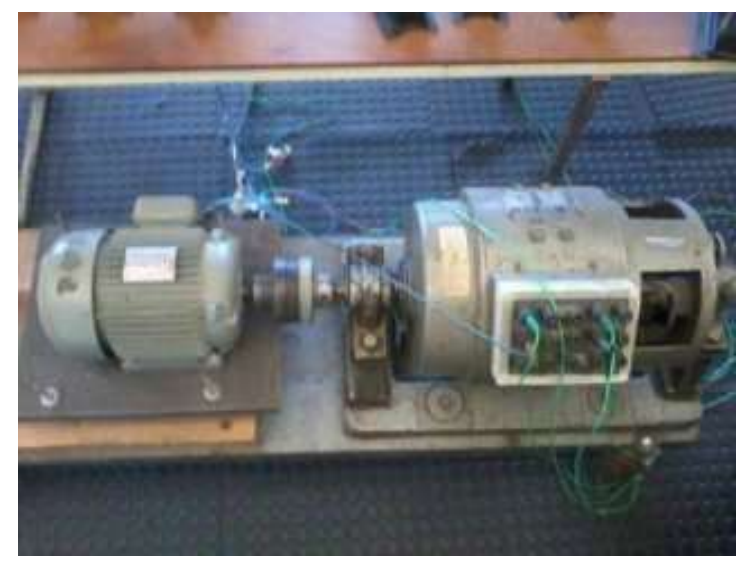

Figure 3. Generator-group: DC motor and an induction generator.

TABLE I. INDUCTION MOTOR USED AS GENERATOR NAMEPLATE

\begin{tabular}{|c|c|}
\hline Power & $1.2[\mathrm{CV}]$ \\
\hline Voltage & $220[\mathrm{~V}]$ \\
\hline Rated current & $3.6[\mathrm{~A}]$ \\
\hline Frequency & $60[\mathrm{~Hz}]$ \\
\hline Speed & $1740[\mathrm{RPM}]$ \\
\hline
\end{tabular}

TABLE II. POSSIBLE COMBINATIONS FOR THE BALLAST LOAD

\begin{tabular}{|c|c|c|c|c|}
\hline \multirow{2}{*}{$\begin{array}{c}\text { Decimal } \\
\text { Number }\end{array}$} & \multicolumn{5}{|c|}{ Binary Number } \\
\cline { 2 - 5 } & $\mathbf{3 0 0}[\boldsymbol{W}]$ & $\mathbf{1 4 1}[\boldsymbol{W}]$ & $\mathbf{7 5}[\boldsymbol{W}]$ & $\mathbf{4 5}[\mathbf{W}]$ \\
\hline 0 & 0 & 0 & 0 & 0 \\
\hline 1 & 0 & 0 & 0 & 1 \\
\hline 3 & 0 & 0 & 1 & 0 \\
\hline 4 & 0 & 0 & 1 & 1 \\
\hline 5 & 0 & 1 & 0 & 0 \\
\hline 6 & 0 & 1 & 0 & 1 \\
\hline 7 & 0 & 1 & 1 & 0 \\
\hline 8 & 1 & 0 & 0 & 0 \\
\hline 9 & 1 & 0 & 0 & 1 \\
\hline 10 & 1 & 0 & 1 & 0 \\
\hline 11 & 1 & 0 & 1 & 1 \\
\hline 12 & 1 & 1 & 0 & 0 \\
\hline 13 & 1 & 1 & 0 & 1 \\
\hline 14 & 1 & 1 & 1 & 0 \\
\hline 15 & 1 & 1 & 1 & 1 \\
\hline & & & & 1 \\
\hline
\end{tabular}

The ballast load was formed by arranging four three-phase lamps, each composed of a combination of lamps in order to form three-phase load power of 45[W], 75[W], 141[W], 300 [W]. 


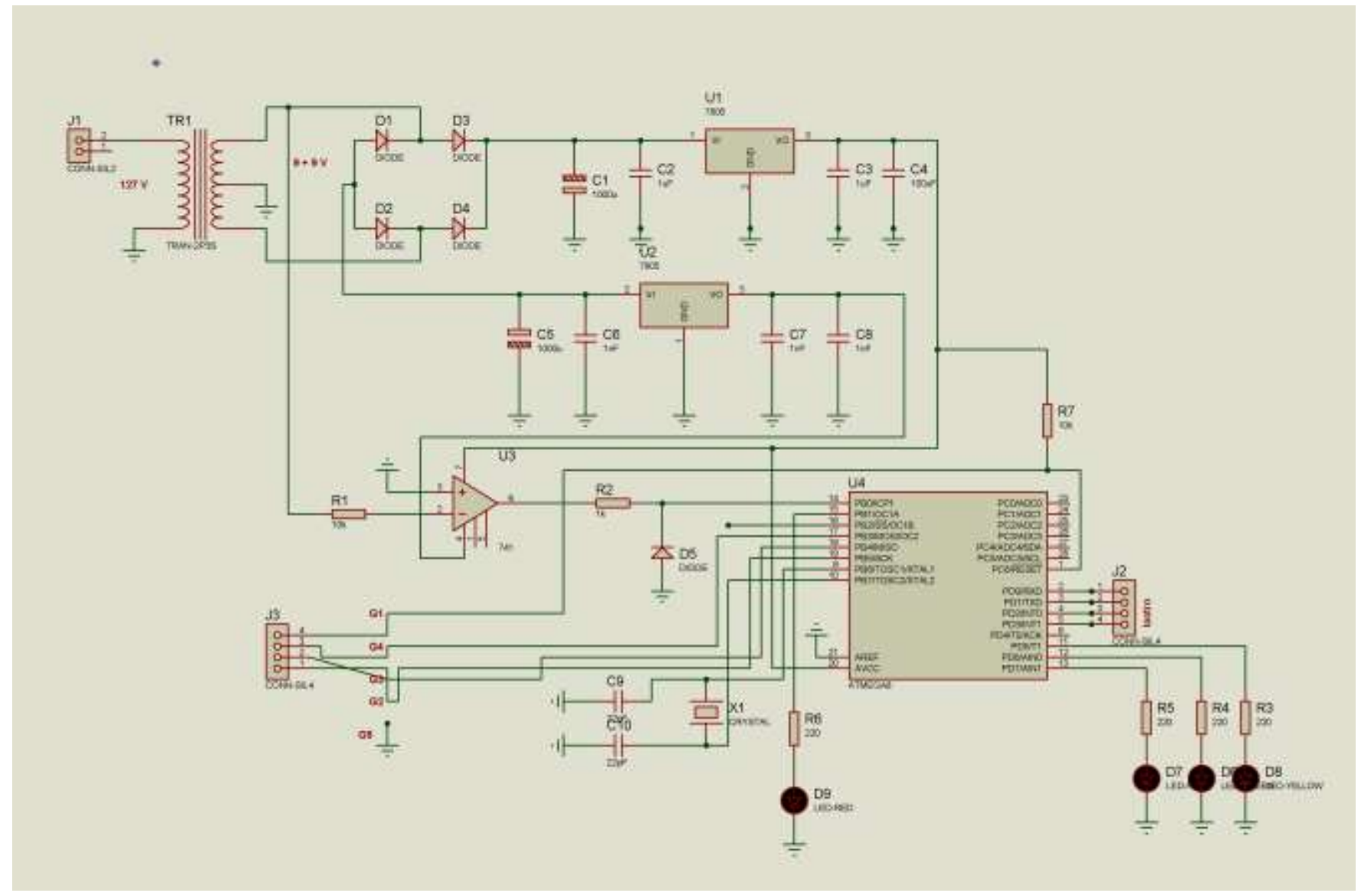

Figure 4. Electronic circuit for frequency control

Initially we set the microprocessor to perform each variation of load at a time of $500[\mathrm{~ms}]$, as a fast frequency response to load variation was expected.

The use of lamps as ballast load was chosen to get a visual result of control and powers were limited to commercial values available. In practice, one can use any resistors and obtain power values.

The logic controller was written in an AVR microcontroller ATMEGA8[4]. This is an 8-bit microcontroller with low-power and ability to execute one instruction per clock cycle due to direct connection with its 32 general registers and with an operating frequency in a 0 to $10[\mathrm{MHz}]$ range. For the insertion of the microcontroller, the electronic circuit shown in Figure 4 was implemented on a printed circuit board. Proteus software was used for simulations [5],[6].

A transformer $220[\mathrm{~V}] / \pm 9[\mathrm{~V}]$ receives the voltage waveform directly from the generator terminals. This signal, through a four-diode bridge rectifier and voltage regulator $+5[\mathrm{~V}]$ and $-5[\mathrm{~V}]$, generating two DC signals, one of $+5[\mathrm{~V}]$ and other $-5[\mathrm{~V}]$, used to power the microcontroller and the operational amplifier 741.

The same alternating signal $9[\mathrm{~V}]$ of the secondary transformer is also sent to the operational amplifier circuit 741 , which turns the sinusoidal wave into a square wave of the same frequency and without the negative side. This wave is sent to the pin 14 of the microcontroller.

The microcontroller programming was done in Pascal. Over a 16-bit counter with frequency "clock" of $10[\mathrm{MHz}]$ divided by 64 , the input signal is compared with the signal "clock" which advances its count whenever the input signal is in a "high" value. The frequency of the voltage is given by (4), with an accuracy of $0.1[\mathrm{~Hz}]$.

$$
\text { Freq }=\frac{10000000 / 64}{\text { counter value }}[\mathrm{Hz}]
$$

Where, Counter value is the value of the counter count.

The frequency value is then compared to a reference range. If the read frequency is above the specified frequency range, a logic signal of 1 is sent to one of the static keys, connecting the ballast load of $45[\mathrm{~W}]$. If the next reading frequency is found even greater value than the specified range, a new logic signal 1 is sent to the corresponding static switch the load of $75[\mathrm{~W}]$ and a signal 0 (zero) for the static switch load 45[W] (see Table II). This process is repeated until the frequency is within the reference range.

LEDs connected to pins 11,12 and 13 indicate the current condition of the system. The red LED indicates a frequency above the specified range, the yellow LED a frequency below the specified range and the green LED a frequency within the reference range. Figure 5 shows ATMEGA8 pin 


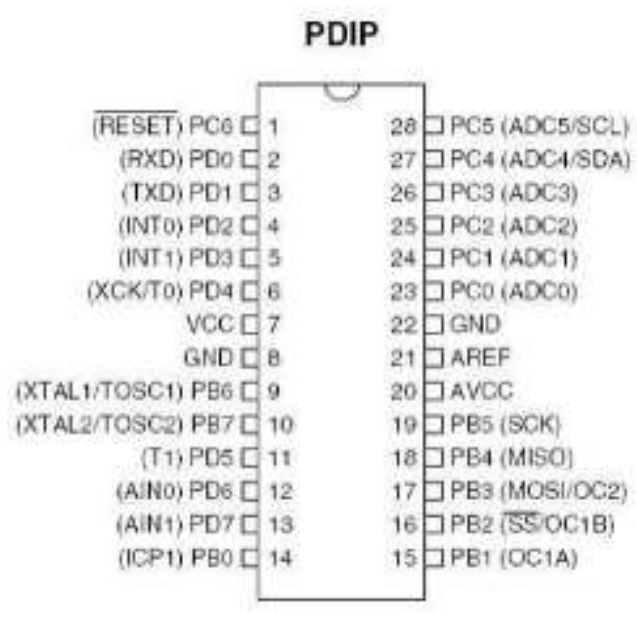

Figure 5. ATMEGA8 pin configuration

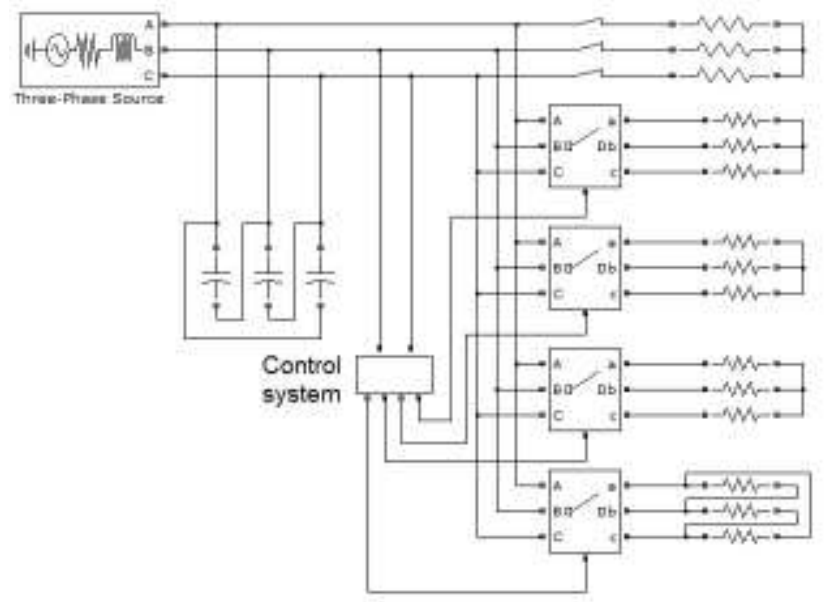

Figure 6. Complete system mounted for frequency control study.

configuration. Finally, the system was mounted for studying and checking the control system, as illustrated in Figure 6.

The three-phase switches of Figure 6 represent the solid state relay or static switches, which are electronic components that are totally solid state, (i.e. not have mechanical parts or any moving parts). The use of these devices eliminates the use of mechanical contactors that wear over time. Figure 7 shows one of the solid state relays (per phase anti-parallel thyristors) used in the system.

\section{Analysis and Results}

The operation of static keys connecting the switch to the power grid and a three-phase load consists of lamps connected in delta was found. By applying a continuous voltage signal of $+5[\mathrm{~V}]$ at its input terminal, the relays are triggered (switches in on state).

The first tests were conducted to verify the operation of the control system and adjust its parameters. Initially, the control is adjusted to maintain the frequency range between $59.5[\mathrm{~Hz}]$ and $60.5[\mathrm{~Hz}]$. However, it was not possible to operate the generator without the voltage rising too much, since the system did not have a voltage control loop, only the frequency

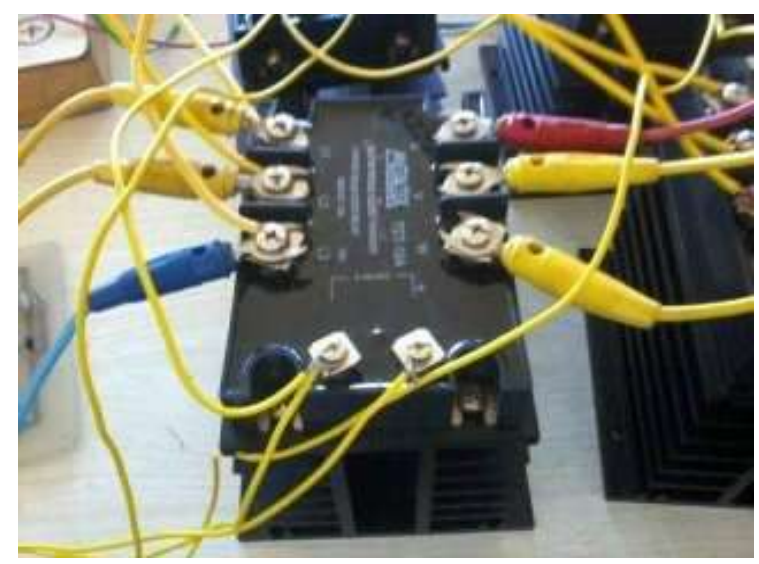

Figure 7. Solid-state relay

TABLE III. VOLTAGE AND FREQUENCY MEASUREMENTS WITHOUT CONTROL

\begin{tabular}{|c|c|c|c|}
\hline & $\begin{array}{c}\text { Load } \\
{[\boldsymbol{W}]}\end{array}$ & $\begin{array}{c}\text { Voltage } \\
{[\text { V] }}\end{array}$ & $\begin{array}{c}\text { Frequency } \\
{[\text { Hz] }}\end{array}$ \\
\hline Full load & 650 & 213.30 & 54.35 \\
\hline & 550 & 224.45 & 54.59 \\
\hline & 500 & 233.40 & 54.07 \\
\hline No load & 450 & 245.00 & 55.25 \\
\hline
\end{tabular}

TABLE IV. VOLTAGE AND FREQUENCY CONTROL MEASUREMENTS

\begin{tabular}{|c|c|c|c|}
\hline & $\begin{array}{c}\text { Load } \\
{[\boldsymbol{W}]}\end{array}$ & $\begin{array}{c}\text { Voltage } \\
{[\text { [V] }}\end{array}$ & $\begin{array}{c}\text { Frequency } \\
{[\text { Hz] }}\end{array}$ \\
\hline Full load & 650 & 201.0 & 54.35 \\
\hline & 550 & 210.45 & 54.45 \\
\hline & 500 & 216.00 & 54.55 \\
\hline & 450 & 214.59 & 54.38 \\
\hline No load & 0 & 228.55 & 54.59 \\
\hline
\end{tabular}

control. The system for a frequency close to $54[\mathrm{~Hz}]$ was set, with the permissible range of $\pm 1[\mathrm{~Hz}]$.

When performing the first tests with the control system, instability was observed in certain systems. When part of the main load was withdrawn, the control system worked, triggering charges according to the binary combinations of Table II. However, in some tests the system could not find a match and keep it, and other times, there were very abrupt variations in load voltage, causing the control system to shut down. Such instability may be the result of the adjusted time between each binary variation reference frequency, even with the absence of a voltage control loop.

In order to reduce these instabilities, changes have been made to the controls, increasing the time interval between each ballast load from $500[\mathrm{~ms}]$ to $2[\mathrm{~s}]$, and reducing the frequency set point of the voltage applied to the load, so as to be $54.0[\mathrm{~Hz}]$, instead of $60[\mathrm{~Hz}]$. Two analyzes, then, took place in order to check the frequency control: a test without control and a test with control. 


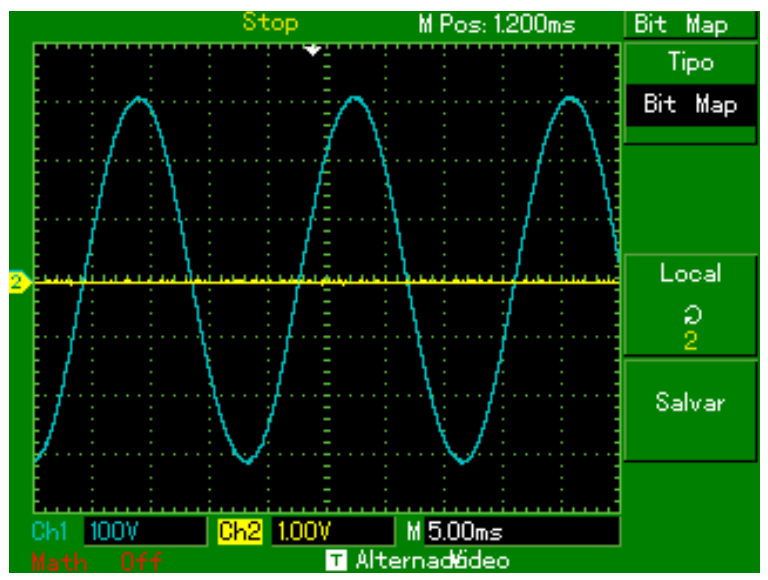

Figure 8 . Voltage shape/waveform at the load with discrete frequency control

\section{A. Test without frequency control.}

In Table III it can be seen that the voltage and frequency vary significantly with the main load change.

\section{B. Test with frequency control.}

Similarly, for test control, voltage and a frequency was set close to 54[Hz] and 220[V]. Several switches to the main load were made, by checking the control through the ballast load, and noting the voltage and frequency values for each. The data are shown in Table IV. As can be seen in Table IV in the control system, the frequency remains almost constant. The voltage change is also reduced, compared to the system without control. This voltage variation is due to the fact that there is not a loop for voltage control to the system. Figures 8 to 14 show photos taken during tests.

Another feasible solution to the problem of frequency stability is through a continuous control, where the control system acts on the firing angle of thyristors in antiparallel to increase or decrease of the power absorbed by the ballast load. Also, we implemented a continuous control in the laboratory, where there was a current injection of harmonic components in the system. For the discrete control system, the voltage applied to the load by means of using an oscilloscope, was observed. Through the waveform shown in Figure 15 a voltage substantially without harmonics can be noted. The waveform virtually free of harmonics is due to the fact that the thyristors of the static keys lead with zero degree angle, that is, there are only two states for the keys: on or off.

\section{Conclusion}

The control system using binary logic and static keys proved to be effective in relation to the one switched system with mechanical contactors, for not presenting wear over time. Another advantage to control the frequency of this system, is not input current harmonics, with respect to a continuous control system, which operates with firing angle modification of the per phase anti-parallel thyristors used in this arrangement[3].
The control used acted only in regard to the frequency, with occurrence of variations in the voltage during the tests. Thus, one can think of using a control voltage in parallel with the frequency, in order to increase the quality of the generated energy. So, as a continuation of this work, we intend to implement a similar control system, also using binary logic, but with voltage control, instead of frequency control. We think that with this control being implemented, it will be more suitable for use in induction generator isolated operation. Really the most important to electrical power supplying of loads is to maintain the voltage almost constant. The frequency can be varied in a acceptable range, when this voltage control is implemented. In Reference [3], this fact was already observed, in the implementation with the application of a controlled ballast load, using per phase anti-parallel thyristors, in micro-hydro power plant rural application.

\section{References}

[1] J. M. Chapallaz, J. D. Ghali, P. Eichenberger, G. Fischer, "Manual on Induction Motors Used as Generators", MHPG Series, Vieweg and Sohns Verlagsgesellshaft, 1990.

[2] A. J. J. Rezek, “ Basic fundamentals of electrical machines: theory and tests" (in Portuguese), Synergia, Acta, Editors, 2011

[3] A. V. Braga, A. J. J. Rezek, A. N. C. Viana, E. C. Bortoni, W. D. C. Sanchez, "Digital control applied to induction generator, isolated operation for use in rural areas" (in Portuguese), $10^{\text {th }}$ IEEE/IAS Conference in Industry Applications (INDUSCON), 2012. http://www.eletrica.ufpr.br/anais/induscon/2012/Data/iREP1588.pdf

[4] DatasheetATmega8, ATMEL

[5] G. R. Marques, L. H. Simões "Frequency control of the induction generator using binary logic" (in Portuguese), Electrical Engineering end of course work, Federal University of Itajubá - UNIFEI, october 2013

[6] G. R. Marques, L. H. Simões, J. M. E. Vicente, J. C. G. Rodrigues, D. F. Bernardes, A. J. J. Rezek, A.V. Braga "Frequency control of induction generator in isolated operation using bynary logic" (In portuguese),hidro \&hydro- PCH Notícias \& SHP News, UNIFEI - CERPCH -Itajubá - Brazil, v. 61, n. 2 , pp. $8-14,2014$.

About Authors:

The authors are with the research group of electrical machines and drives - Electrical Engineering Institute - UNIFEI. 